\title{
Correlation of Rangelands Brush Canopy Cover with Land- sat MSS Data
}

\author{
W.E. BOYD
}

\section{Abstract}

Traditional methods of monitoring brush canopies such as ground survey and aerial photography are not cost effective for large areas. This experiment compared photo-estimated brush canopy closure to Landsat MSS derived vegetation indices. Several vegetation indices were found to be highly correlated to brush canopy cover. The vegetation index which was most highly correlated with brush canopy cover was the GB ratio (Kauth and Thomas Greenness/Kauth and Thomas Brightness, $r=0.813$ ). These results suggest that brush canopy cover can be quantified through the use of the Landsat MSS data; however, further research is necessary to determine the transportability between sites of green biomass/brush canopy quantification indices.

Expansion of brush populations is a major problem confronting range and other resource managers. Traditional methods of monitoring brush make extensive use of ground surveys (MuellerDombois and Ellenberg 1974) and aerial photographic techniques (Tueller et al. 1972).

Plants differentially reflect incident electromagnetic energy. Green light (the dominant wavelength of energy emitted by the sun) is reflected while blue and red light are absorbed by chlorophyl. Healthy plants reflect highly in the infrared due to internal leaf scattering (Knipling 1969) caused by their internal cellular structure. Vegetation indices are contructed by combining spectral measurements a 2 or more wavelengths. Several researchers (Rouse et al. 1974, Holben et al. 1980, Kimes et al. 1981) have shown that ratios developed from reflected energy in the red and near-infrared wavelengths relate closely to vegetation parameters such as green biomass, leaf area index (LAI), and percent foliar cover. Generally, the greater the amount of green biomass, the larger the value of the infrared to reflectance ratio.

Scientists have utilized the data available from the red and near-infrared wavelengths to make quantitative estimates of plant green biomass (Pearson and Miller 1972). Rouse at al.(1974) used a normalized ratio of near-infrared/red Landsat data (Bands 6 and 5 respectively) to evaluate the vernal advancement and retrograda-

\footnotetext{
Author was research associate, Remote Sensing Center, Texas A\&M University, College Station 77843. Currently with USDA Foreign Agriculture Service, Washington, D.C.

This research was partially supported by the Texas Agricultural Experiment Station and the University of Texas Lands Surface Interests Office, Interagency Cooperative Contract 1690 .

Manuscript accepted 14 August 1985.
}

tion (green wave effect) of range vegetation at several test sites throughout the Great Plains corridor. Correlation analyses between clipped green biomass and normalized infrared/red Landsat data produced correlation coefficients of up to $r=0.91$. A strong correlation $(r>0.89)$ between this ratio and plant greenness parameters also exists for row crops (Holben et al. 1980, Kimes et al. 1981).

Vegetation indices other than simple or normalized ratios of Landsat bands have been developed by several scientists. The best known of these is by Kauth and Thomas (1976). They developed a four-index method for interpreting the spectral-temporal structure of Landsat data. All 4 channels of Landsat data are used in making the Kauth and Thomas data transformation. Two of their 4 indices are related to plant greenness and soil brightness.

Harlan and Deering (1979) found that regression coefficients relating green grass biomass to vegetation indices based upon satellite data from sites with brush cover were significantly lower than from sites with no brush cover. These results occurred because the vegetation indices were calculated from the combined reflectance of the green grass and green brush canopy while only the green grass was sampled for production. These investigators were interested only in the correlation between green grass biomass and satellite data. Deering and Haas (1980) suggested that by using the known phenological development of brush species it might be possible to selectively map brush species within a rangeland scene using Landsat data.

McDaniel (1978) used Landsat data to follow the relative greenness of 2 sites, one with brush ( $>15 \%$ canopy cover) and one without ( $<1 \%$ brush cover), for a 1-year period. He reported that mesquite canopies stay green and are detectable relative to grass during a dry summer. Musick (1983) reported that the combined cover of mesquite and broom snakeweed on the Jornada Experimental Range were correlated $(r=0.77)$ with green vegetation indices in June when grasses and other vegetation were in droughtinduced dormancy.

The objective of this research was to determine the relationship between vegetation indices calculated from Landsat MSS radiance measurements and green brush canopy cover.

\section{Materials and Method}

\section{Study Area}

The W.T. Waggoner Ranch lies in the Rolling Plains resource 
area of Texas. The major soil association in the study area is the Tillman-Vernon association (Rogers et al. 1971). Climax herbaceous vegetation on the study site consists mainly of mid and short grasses. Dominant grasses are reported to be side oats grama (Boutelua curtipendula Mich.), vine mesquite (Panicum obtusum H.B.K.), blue grama (Boutelua gracilis H.B.K.), and buffalo grass (Buchloe dactyloides Nutt) (Rogers et al. 1971). The major woody vegetation consists of mesquite (Prosopis glandulosa Torr.), lote bush (Condalia obtusifolia (Hook) Weberb.), and along the creeks, hackberry (Celtis laevigata Willd.) (Gould 1975). Range conditions of the pastures used in this experiment were fair to good (Dick Yeager, personal communication).

\section{Photography}

Archival color infrared photography of the Waggoner ranch (acquired June, 1979) covers approximately 4,800 hectares in the southeastern portion of the ranch. The nominal scale is $1: 12,000$. The photography was previewed and 25 homogeneous brush covered areas were selected (Fig. 1). The plot size ranged from

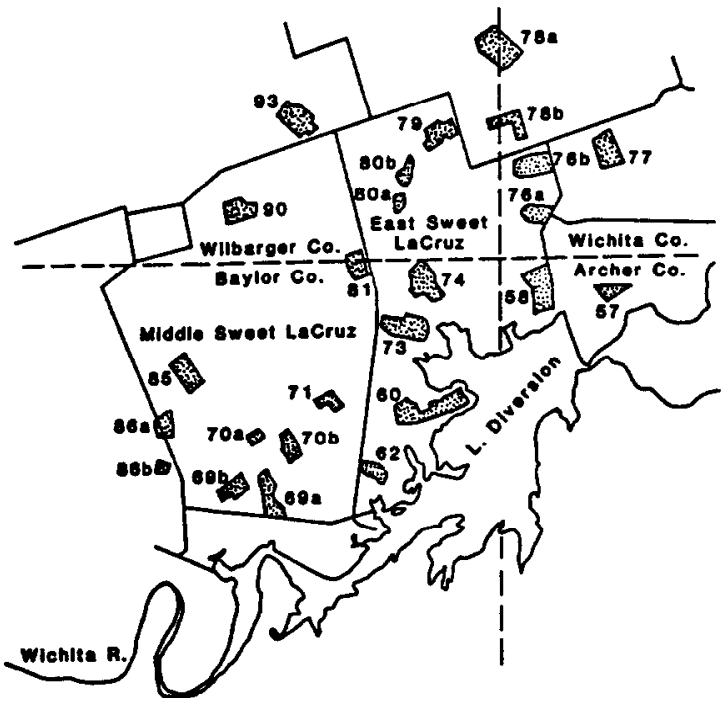

Fig. 1. Approximate location of specific control sites used to correlate Landsat MSS data to brush canopy cover.

approximately 8 to 153 hectares. Canopy cover estimation of these areas was accomplished by manual enumeration through a $3 \mathrm{X}$ binocular microscope using a dot grid of 100 dots per square centimeter. At this scale each dot represents approximately 0.0356 hectares. The dot grid was fitted over a brush canopy test area image and a count made of the number of dots which fell upon tree canopies. A calculation was then performed (dots upon trees/total dots per area) to estimate brush canopy percentage for the sample site (Table 1).

\section{Landsat}

Summers in this region are typically hot and dry with high evaporation and transpiration rates. Due to the lack of significant precipitation for a lengthy period during the summer, the grass understory becomes dormant (browns down) when the near surface moisture is depleted. Mesquite and other deeper rooted shrub species draw from deep moist soils and stay green during the "summer drought."

The NOAA weather records (Mitchell 1978) for the 3 closest reporting stations (Seymour, Wichita Falls, Vernon) were consulted (Table 2). In order to maximize results for this type of investigation with Landsat data, it was essential that the grass understory be as brown as possible. Landsat scene number $30232-$ 16352 for July 15,1978 , was selected on the basis of low cloud cover and the long period without rainfall prior to scene acquisition. It should be noted that a 1978 scene was chosen rather than one from
Table 1. Brush canopy estimates and area of control sites used for correlations with Landsat MSS Data.

\begin{tabular}{ccc}
\hline \hline Plant No. & Estimated canopy $\%$ & Hectares \\
\hline 57 & 42 & 39 \\
58 & 4 & 109 \\
60 & 29 & 153 \\
62 & 33 & 34 \\
$69 \mathrm{a}$ & 39 & 37 \\
$69 \mathrm{~b}$ & 25 & 41 \\
$70 \mathrm{a}$ & 13 & 18 \\
$70 \mathrm{~b}$ & 25 & 55 \\
71 & 9 & 36 \\
73 & 31 & 98 \\
74 & 35 & 132 \\
$76 \mathrm{a}$ & 31 & 49 \\
$76 \mathrm{~b}$ & 45 & 89 \\
77 & 43 & 8 \\
$78 \mathrm{a}$ & 53 & 100 \\
$78 \mathrm{~b}$ & 40 & 70 \\
79 & 37 & 63 \\
$80 \mathrm{a}$ & 30 & 39 \\
$80 \mathrm{~b}$ & 47 & 31 \\
81 & 44 & 68 \\
85 & 8 & 61 \\
$86 \mathrm{a}$ & 9 & 43 \\
$86 \mathrm{~b}$ & 17 & 36 \\
90 & 24 & 40 \\
93 & 16 & 87 \\
\hline & & \\
\hline
\end{tabular}

Table 2. Rainfall data for 1978 from three reporting stations.

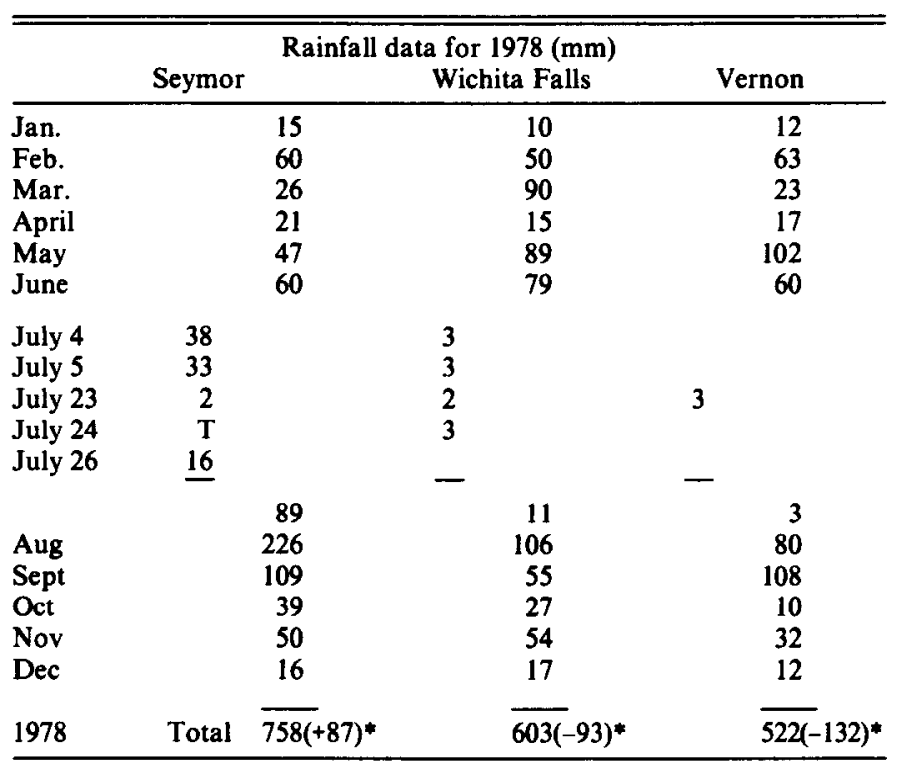

* Deviations of the yearly total from the yearly normal.

1979 because a rangeland herbicide was applied to brush canopies in the test area on approximately July 1, 1979 resulting in brush canopy cover reduction.

The Landsat tape was viewed and the area of the scene covered by aerial photography rectified to remove skew. ${ }^{1}$ After skew removal, the I andsat data for the study were stored on computer disc for future use in image processing. In order to guarantee that the area of each canopy sample site corresponded as closely as possible to the satellite scene, each sample site was delineated on a 1:24,000 scale U.S. Geological Survey quadrangle map of the area. Map

'Skew in Landsat data results from the rotation of the earth during the time in which a scene is scanned. In order for the data to be geometrically correct relative to the ground this distortion must be removed. 
data were then entered into the computer via a video digitizer and were geometrically fitted to the Landsat scene. Raw, unscaled pixel statistics for each band for each site were extracted by outlining the sites on the digitized map and having the computer print the statistics for the corresponding areas from the geometrically corrected Landsat subscene.

Kauth and Thomas developed their indices and transformation coefficients for Landsat 2; these coefficients are not available for Landsat 3. The data for this study were acquired by Landsat 3 . It was necessary to transform the raw digital count data from Landsat 3 to Landsat 2 using the following equation and coefficients (Thompson and Wehamen 1980) prior to calculating the Kauth and Thomas indices.

where

$$
\text { Landsat } 2 \text { Band (i) = Landsat } 3 \text { Band (i) } \times \mathrm{CF}(\mathrm{i})
$$

$$
\begin{aligned}
\mathbf{i} & =4,5,6,7 \\
\text { CF4 } & =1.116 \\
\text { CF5 } & =1.23 \\
\text { CF6 } & =1.246 \\
\text { CF7 } & =1.062
\end{aligned}
$$

Raw, unscaled Landsat pixel averages were used to compute the various vegetation index values for each site (Table 3). Vegetation index values were then regressed against brush canopy estimates.

Table 3. Vegetution algorithms calculated for this study.

S6 [Richardson and Wiegand 1977] = Band 6/Band 5

S7 [Richardson and Wiegand 1977] = Band 7/Band 5

ND6 [Richardson and Wiegand 1977] = (Band 6-Band 5)/(Band 6+Band 5)

ND7 [Richardson and Wiegand 1977] $=($ Band $7-B a n d ~ 5) /(B a n d ~ 7+B a n d ~ 5)$

Difference difference (DD) [Jackson et al. 1938] $=(2 \cdot$ Band 7)-Band 6Band 5-Band 4

Kauth and Thomas Greenness (KTGr) [Kauth and Thomas 1976] = $-($ Band $4 \bullet 0.28317)-($ Band $5 \bullet 0.6606)+($ Band $6 \bullet 0.57735)+($ Band $7 \cdot 0.38833)$

Kauth and Thomas Landsat Brightness (KTBr) [Kauth and Thomas 1976) $=($ Band $4 \cdot 0.33231)+($ Band $5 \cdot 0.60316)+($ Band $6 \cdot 0.67581)+($ Band $7 \cdot 0.26278$ )

Greenness Brightness Ratio (GB) [personal communication, J.L. Heilman] = KT Greenness/ KT Brightness

$\mathrm{GBa}$ [Personal communication, R.W. Newton] $=(\mathrm{KT}$ Greenness $)-(\mathrm{KT}$ Brightness)

\section{Results}

The results of the linear correlation between brush canopy cover and satellite data ratios (Table 4) indicate that all of the calculated vegetation indices except Kauth and Thomas'Brightness and $\mathrm{GBa}$ are highly correlated $(P R>F=0.0001)$ to brush canopy cover. The vegetation index which gave the best correlation was the $\mathrm{GB}$ ratio $(r=0.813)$. A regression line plot of the data appears as Figure 2.

Table 4. Landsat MSS vegetation index values regressed against estimated percent brush canopy $(n=25)$.

\begin{tabular}{lccccc}
\hline \hline Image Date & Index & $\boldsymbol{r}$ & $\boldsymbol{r}^{2}$ & $\boldsymbol{F}$ value & $\operatorname{Pr}>\mathrm{F}^{* *}$ \\
\hline July 15, 1978 & GB & $\mathbf{0 . 8 1 3}$ & $\mathbf{0 . 6 6 1}$ & 44.90 & .0001 \\
& ND6 & 0.806 & 0.651 & 42.95 & .0001 \\
& S6 & 0.801 & 0.642 & 41.30 & .0001 \\
& DD & 0.795 & 0.633 & 39.79 & .0001 \\
& ND7 & 0.793 & 0.629 & 39.00 & .0001 \\
& S7 & 0.784 & 0.615 & 36.77 & .0001 \\
& KT Gr & 0.757 & 0.574 & 31.05 & .0001 \\
& GBa & 0.657 & 0.432 & 17.53 & .0004 \\
& KT Br & 0.423 & 0.179 & 5.03 & .0348 \\
\hline
\end{tabular}

$* * \mathrm{Pr}>\mathrm{F}$ is the probability that the $F$ value is greater than the standardized table value.

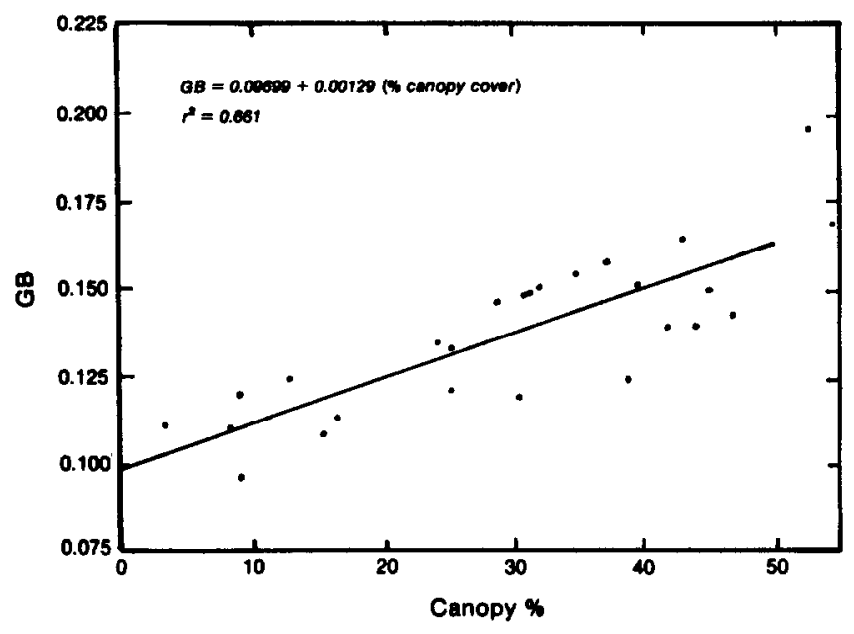

Fig. 2. Greenness Brightness index (GB) versus percent canopy cover.

These data indicate that while the GB model explained the largest amount of scene variability $\left(r^{2}=0.661\right)$, any of several indices could be used on this site. These results compare favorably with Hutchinson et al. (1982) Arizona mesquite canopy study. The results also compare favorably with other results (Holben et al. 1980, Musick 1983) for correlations between green biomass, LAl, and green plant canopy cover for both rangeland and row crops. These data indicate that a statistically significant relationship exists between several Landsat MSS vegetation indices and brush canopy cover. Management applications involving Landsat based brush canopy estimates are numerous. This estimation technique should be especially useful to managers of large land areas where regularly repeated area photography acquisition for brush canopy quantification is deemed too expensive. Multi-year comparisons of brush canopy changes should also be possible.

Accuracy assessment of satellite based canopy estimates is very desirable. Such assessment was not possible with this data set because the study was conducted in 1982 using historical data and a rangeland herbicide had been applied in 1979. Future experiments should be designed to include such assessment.

A major problem which must be addressed before the full range of applications involving canopy estimation can be realized is that of regression relationship transportability. In this context, "transportability" refers to the development of a regression relationship between a vegetation parameter and satellite data on a site and its use on other sites. Several investigators (Harlan and Deering 1979, Barnett and Thompson 1982) have documented that vegetation index regression relationships shift from site to site and date to date. These shifts affect the estimation accuracy of the various indices. At this time research findings conflict with respect to vegetation index sensitivity to changes in soil color associated with different sites. Some researchers (Thompson and Wehmanen 1980, Boyd and Heilman 1985 submitted) suggest that a Kauth and Thomas based Greenness index is the least affected by soil color changes. Jackson et al. (1983) report that the 7/5 (S7) ratio is less sensitive. The research questions concerning the transportability of vegetation indices for natural resource applications are numerous and unresolved.

\section{Conclusions}

The data in this study indicate that green brush canopy cover is correlated to Landsat MSS data. At this time, field accuracy assessment of Landsat based canopy estimates has not been undertaken. Further research is necessary to determine the transportability between sites of green biomass/brush canopy quantification indices. 


\section{Literature Cited}

Barnett, T.L., and D.R. Thompson. 1982. The use of large-area spectral data in yield estimation. Remote Sensing of Environ. 12:509-518.

Boyd, W.E., and J.L. Heilman. 1985. Simulating soil color effects upon vegetation indices. Remote Sensing of Environ. (Submitted).

Deering, D.W., and R.H. Haas. 1980. Using Landsat data for estimating green biomass. NASA/ Goddard Space Flight Center, Technical Memorandum 80727. Greenbelt, $M d$.

Gould, F.W. 1975. Texas Plants-A check list and ecological summary. Report MP-585, Texas Agricultural Experiment Station. College Station.

Harlan, J.C., and D.W. Deering. 1979. Applied monitoring of the vernal advancement and retrogradation (greenwave effect) of natural vegetation. Remote Sensing Center, Final Report RSC 3108-7. Texas A\&M University, College Station.

Holben, B.N., C.J. Tucker, and Cheng-Jen Fan. 1980. Spectral assessment of soybean leaf area and leaf biomass. Photo. Eng. and Remote Sensing 46:651-656.

Hutchinson, C.F., L. Leight, and M.C. Parton. 1982. Mesquite cordage mapping from Landsat digital data. Arizona Remote Sensing Center, University of Arizona, Tucson.

Jackson, R.D., P.N. Slater, and P.J. Pinter, Jr. 1983. Discrimination of growth and water stress in wheat by various vegetation indices through a clear and turbid atmosphere. Remote Sensing of Environ. 13:187-208.

Kauth, R.J., and G.S. Thomas. 1976. The tasseled cap-A graphic description of the spectral-temporal development of agricultural crops as seen by Landsat. Proc. Symp. on Machine Processing of Remotely Sensed Data, LARS, Purdue Univ., West Lafayette. Ind.

Kimes, D.S., B.L. Markham, C.J. Tucker, and J.E. MeMurtrey. 1981. Temporal relationships between spectral response and agronomic variables of a corn canopy. Remote Sensing of Environ. 11:401-411.

Knipling, E.B. 1969. Physical and physiological basis for the reflectance of visible and near-infrared radiation from vegetation. Remote Sensing of Environ. 1:155-159.
McDaniel, K.C. 1978. Evaluation of Landsat MSS data for classifying and characterizing natural vegetation on a regional basis. Diss. Range Science Department, Texas A\&M University, College Station .

Mitchell, D.B. 1978. Climatological Data-Texas. U.S. Department of Commerce-NOAA-Environmental Data Service, National Climatic Center, Ashville, N.C.

Mueller-Dombois, D., and H. Ellenberg. 1974. Aims and methods of vegetation ecology. John Wiley \& Sons. New York.

Musick, H.B. 1983. Assessment of MSS spectral indices for monitoring arid rangeland. IEEE-International Geosciences and Remote sensing Symposium (IGARSS) Vol. 2 Session PS-2:6.1-6.6.

Pearson, R.L., and L.D. Miller. 1972. Remote spectral measurement as a method for determining plant cover. U.S./IBP Grassland Biome Tech. Rep. No. 167. Colorado State University, Fort Collins.

Richardson, A.J., and C.L. Wiegand. 1977. Distinguishing vegetation from soil background information. Photo. Eng. and Remote Sensing 43:15411552.

Rogers, C.A., G.D. Passmore, and W.M. Risinger. 1971. Soil Survey of Baylor County, Texas. USDA-Soil Conservation Service.

Rouse, J.W., Jr., R.H. Hans, J.W. Schell, D.W. Deering, and J.C. Harlan. 1974 Monitoring the vernal advancement and retrogradation (greenwave effect) of natural vegetation. Remote Sensing Center, Final Report RSC 1978-4, Texas A\&M University, College Station.

Thompson, D.R., and O.A. Wehmanen. 1980. Using Landsat digital data to detect moisture stress in corn-soybean growing regions. Photo. Engr. and Remote Sens. 47:1087-1093.

Tueller, P.T., G. Lorain, K. Kipping, and C. Wilkie. 1972. Methods for measuring vegetation changes on Nevada rangelands. Nevada Agr. Exp. Sta. Publication T16, University of Nevada, Reno. 